\title{
DIFFERENTIAL GENETIC ADVANTAGES IN YOUTH AND IN AGING, OR HOW TO DIE HEALTHY
}

\author{
Hilal S. Khalil' ${ }^{1}$, Rumena Petkova², Nikolai Zhelev ${ }^{1}$ \\ ${ }^{1}$ University of Abertay Dundee, School of Contemporary Sciences, Cancer Systems Biology, Scotland, UK \\ ${ }^{2}$ Scientific Technological Service (STS Ltd.), Sofia, Bulgaria \\ Correspondence to: Rumena Petkova \\ E-mail: rumenapetkova@yahoo.com
}

\begin{abstract}
Human society ages at a steady rate, that is, the proportion of adult and elderly individuals increases constantly because of improved living conditions and the advances in medical care. This means that very soon the tradeoff between the advantages in old age conferred by alleles disadvantageous or neutral in young age would begin to show, providing the fascinating opportunity of studying the interplay between genetic factors and environment outside the framework of reproductive capacity and in the unique milieu of the aging cell. Being healthy and/or health-conscious in youth does not guarantee for successful aging or even that the person would live up to the average life expectancy of the population. Therefore, successful aging and longevity are related to a healthy-conscious attitude to a degree only. The present paper reviews the basic genetic and evolutionary mechanisms which have operated during human history so as to ensure survival of humankind and the possible factors preventing or contributing to successful aging.
\end{abstract}

Biotechnol. \& Biotechnol. Eq. 2012, 26(1), 2703-2711

Keywords: differential aging, antagonistic pleiotropy, DNA repair, molecular evolution, diseases of aging

\section{Not getting older, getting better: the concept of successful aging}

I wasted time, and now doth time waste me.

William Shakespeare, Richard II (1595). Act V, scene 5.

Successful aging is a relatively recent scientific term that may sound jarringly unusual or controversial, as aging has always been described as anything but 'successful'. According to Erickson's personality theory (26), later adulthood and subsequent old age is the time of the 'integrity vs. despair' crisis, when the final developmental task of retrospection and assessment of one's lifelong achievements and/or failures takes place, as well as dealing with loss and general preparation for death. If we look carefully at the age structure of any modern society though, we would not find many healthy elderly adults that are content just with peaceful contemplation of their past lives. A significant proportion of people aged 65 years or more remain healthy, active physically and mentally and contribute to their families, their jobs and the society in a unique way. Improved healthcare, higher general level of education, the opportunity for lifelong learning and the increased ages of marriage and childbirth have contributed greatly to this tendency and have eventually made it global.

The average lifespan of humans has only extended beyond middle-to-late adulthood in the last $100-150$ years, largely because of the successes of the modern medicine in the prevention and treatment of infectious disease and the development of anti-inflammatory therapy. Successful aging, however, has been recognized, respected, and, often, revered, throughout human history. After all, Michelangelo finished his larger-than-life Pietà del Duomo at the age of 80 and would have probably finished his Pietà Rondanini, had he not made that unfortunate horseback promenade in the rain after a day's hard work at the age of 88 (64). Lorenzo da Ponte, the famous opera librettist and poet, who wrote for over 10 composers, produced the first New York public performance of Mozart's Don Giovanni in 1826, at the age of 77 (over three decades after Mozart died - at the age of 35) and published his 'Versi composti' at the age of 83 (36). James Watson, one member of the famous duo that gave us the double helix model of the structure of DNA, published his Avoid Boring People: Lessons from a Life in Science in 2007, at the age of 79. The list of people who created truly spectacular works in their advanced age can thus go on for a long time.

The formal concept of successful aging is not exactly new either. The standard definition is quite straightforward and is usually defined in terms of an individual retaining the ability to function independently in advanced age $(71,72,84)$. More specifically, it has been described as 'multidimensional process encompassing the avoidance of disease and disability, the maintenance of high physical and cognitive function, and sustained engagement in social and productive activities' $(65,73)$. Understandably, the individual parameters of this description would be differently prioritized and differentially achieved in different people and the need for assistance would increase with progressing age. In any case, however, old age is not necessarily the time for regret and disability; it could be productive and gratifying to the aging persons, their families and the human society as a whole.

All the progress in modern medicine and all the "healthy living' obsession notwithstanding, however, successful aging is 
still reserved to chosen few. Among these the careful observer could spot apparently 'unhealthy' lifelong habits and general happy-go-lucky approach to personal health at a rate practically indistinguishable from the rate in the general population. The search for the basis of this apparent discrepancy between conscious attempts to live 'healthy' and actual longevity and general health in old age has only begun. It is believed that at least part of the reason why not all healthy young people become eventually healthy old people is the phenomenon of antagonistic pleiotropy.

\section{Antagonistic pleiotropy: where has all this natural selection brought us?}

Too much of the good thing can be taxing. Mae West (1893-1980)

Natural selection results in survival of the fittest. This has been taught for decades now, and is essentially true (or as true as a generalization could be). The flaw in that concept, unfortunately, is demonstrated daily by the mundane fact that it is rarely the case that the fittest, healthiest, most vigorous young individuals age more successfully and live longer than their less fit counterparts. Barring potential confounding variables such as the incidence of work and vehicle incidents (which tend to be more common in youths than in adults, peaking again after age $65-70(33,67))$, statistics shows that annual mortality peaks between the age of 35 and 45 for both sexes, decreasing smoothly until age $85-90$ and peaking again for females while remaining at a plateau for males $(20,45,69)$. It could be hypothesized that some genetic traits that provide advantages at young age may become disadvantageous in mature and old age. Thus, a tradeoff could be proposed between the ability to survive to maturity and reproduce and the ability to survive long after the reproductive plans have been completed. Differential impact of individual genetic background in different ages could explain the fact that a certain percentage of the average healthy individuals, who thrive in childhood, develop successfully and produce healthy offspring, actually die before reaching middle adulthood while at the same time certain individuals do reach very old age.

The idea of the tradeoff of genetic traits at different life stages (antagonistic pleiotropy) has been first expressed back in 1957 in an attempt to explain the phenomenon of aging (90). Presumably, longevity and successful aging are dependent on a set of pleiotropic genes. Certain alleles of these genes ensure and promote fitness in young individuals, causing them to be selected and retained in the gene pool via reproduction. Same gene variants, however, result in poorer overall health and limited longevity in adults. Williams exhibited a remarkable insight, considering that in the $50 \mathrm{~s}$ of the XX century the foundations of modern genetics have hardly been laid. He proposed that the selection pressure over a gene that in its different allelic forms confers an advantage at one age and a disadvantage at another is dependent both on the magnitudes of the effects themselves and on the timing of the effects, that is, an advantage provided during the period when successful reproduction is most probable would increase the total probability of positive selection for the respective gene variants (by passing them to the offspring) more than a proportionately similar disadvantage later on would decrease it. It makes perfect sense even in modern terms, as the allele pool diversity in the populations is maintained primarily by passing alleles on to the progeny (in cases when the carriers of these alleles are fit enough to reach maturity and reproduce). New alleles may also be introduced by de novo mutations, including the case when the alleles in question result in severe disability or early death precluding reproduction.

In any case, however, any genetic advantage that causes delay in the loss of reproductive probability increases the positive selection for the associated pleiotropic genetic traits. For example, it is well known that the number of ovarian follicles in women decreases with age, reaching the critical number of about 1000 about the age of 51, which is the median age of onset of menopause (32). The loss of follicles actually starts early in life, but the rate of attrition is relatively stable throughout youth and early adulthood, until the average age of 37-38, when the rate of follicle loss accelerates and the onset of menopause is triggered approximately a decade later (85). Factors that may slow down the rate of decline in reproductive probability (in this case, the rate of follicle attrition) intensifies positive selection, that is, women who can still ovulate at a later age have increased chances to pass their genes to the potential offspring. The overall result is that the peak of female fecundity and fertility is situated roughly between the ages of 20 and 30 and is common for most healthy females, but as age advances, the reproductive probability (i.e. fecundity) becomes more and more individually specific, with some women entering the menopause as early as 45 while others retain their menstrual cycle, may get pregnant and carry the pregnancy to term up to 50 years and beyond (though this is rare and the probability for it declines with every year after the fertility peak). Apart from cases where egg and embryo donation are used as means to resolve an infertility problem, fertility treatments in later adulthood require that the ovarian reserve is maintained beyond the age at which the accelerated follicle attrition starts, delaying reproductive senescence (that is, menopause). Without any intervention targeted at resolving the ovarian reserve issues, the major proportion of alleles in the gene pool would be due to births from mothers in the fertility peak. With the advent of IVF, however, the percentage of children born from previously infertile couples steadily increase every year, which means that at least a proportion of the genetic pool of today and in the future would be made of alleles which do not confer reproductive advantage; otherwise at least some of their carriers would have had a better chance to reproduce naturally. In summary, in a society with less-thandeveloped medical care the process of antagonistic pleiotropy would select for individuals who exhibit high physical and reproductive fitness in their young age (working on premises of natural selection only), but in a society equipped with state-of-the-art medical arsenal, it would also work for 
positive selection for individuals that retain their vigour and reproductive fitness longer than others.

Another consequence of antagonistic pleiotropy would be that in the absence of medical care (e.g. wild animal populations, primitive human societies) post-reproductive periods be short and/or unusual. This is easily demonstrable. For example, unspayed females of domesticated animals such as dogs usually are capable of oestrus and sometimes of getting pregnant until very old age - that is, $10-12$ or more years (sometimes until their death), though fertility eventually wanes away. For comparison, their counterparts living in the wild rarely live over 7-8 years, which means that at the time of their death they are still fully capable of reproduction.

It has been proposed that the selection related to the likelihood to reproduce and the reproductive competitiveness has been driven towards individuals who are reasonably immunologically competent when young (that is, resistant to infectious disease), so that they could survive infant and adolescent stage and reach age when they can successfully produce progeny. Increased immune reactivity in earlier age, however, seems to bring about unfavourable effects at a later age. For example, in European populations the prevalence of the so-called AH8.1 or 'super-B8' HLA haplotype (A1-B8DR3) is quite high (5-20\%, depending on the population). AH8.1 as a whole and the separate serotypes which constitute it have been found to be associated with increased risk for an impressive number of autoimmune diseases (diabetes type 1 - DR3, myasthenia gravis - B8, DR3; Graves disease and multiple endocrine autoimmunity - B8, DR3; systemic erythematous lupus - B8, DR3; celiac disease - B8, DR3) as well as increased risk for some types of cancer $(8,9,29,66)$. Obviously, having any of these conditions at any age does not exactly contribute to successful aging, even with modern medical care. AH8.1 is rarely seen indeed among the middleold and the oldest old (over 75 years) but nevertheless it is present at a rate of several per cent. Its effect on longevity and successful aging seems to be modulated by other factors, among which are gender differences (women are more predisposed to autoimmune disease than men) and/or others $(10,11,60)$. Thus, the common European A1-B8-DR3 haplotype might be initially selected for its early positive effects, but as it is associated with a susceptibility to a variety of diseases in adulthood, the selective advantages it confers to the carrier actually diminish as young progresses into mature age. If, however, AH8.1-associated immune dysfunctions had not developed until the beginning of old age, it is possible that its positive effects with regards to resistance to infections would continue, contributing to the successful aging process to the fewer AH8.1-carriers who have eluded autoimmunity.

The number of adult and elderly individuals increases constantly worldwide because of improved living conditions and the advances in medical care. This means that, sooner rather than later, the tradeoff between the advantages in old age conferred by alleles disadvantageous or neutral in young age would begin to show, providing the fascinating opportunity of studying the interplay between genetic factors and environment outside the framework of reproductive capacity and in the unique milieu of the aging cell.

\section{Differential role of DNA repair in aging}

The time to repair the roof is when the sun is shining. John F. Kennedy (1917-1963)

Constant, systematical, efficient repair of DNA damage is considered to be the main mechanism of protection of living cells against potentially harmful modification of the blueprint of their major information carrier molecule. Accumulation of DNA damage is believed to play a major role in the processes of aging and, ultimately, death, as well as in triggering and promoting cancerous growth. At a glance, the optimal mode of action to delay or arrest cellular aging might seem pretty straightforward - making sure that the cells are maximally protected from the impact of DNA damaging agents. It turns out, however, that this will not be practical and is unlikely ever to work, for a variety of reasons. First, the amount of DNA damage that the cell needs to manage daily is generated under the influence of external factors as well as by internal physiological processes. For example, only the spontaneous occurrence of abasic sites accounts for some $5 \times 10^{3}-10^{4}$ events per eukaryotic cell per day $(25,53)$ and this is only one very simple type of DNA damage that the cellular machinery knows how to recognize and repair. Second, it has been known for more than two decades that in some cells the repair of DNA is carried out preferentially on the actively transcribed genes only, selectively inhibiting the repair in nontranscribed chromatin $(6,34,35)$. Later, it has been proposed that in some terminally differentiated cells (i.e. cells which are unlikely to divide any more in their lifespan, such as mammalian neurons) this is not merely a consequence of the more dense, and, therefore, less accessible chromatin structure in the untranscribed DNA regions, but an active compromise between focusing the capacity of the cellular repair machinery on managing the DNA damage that is present at the moment in genes important for the function of the cell versus diverting a significant proportion of this capacity to checking and repairing damage that is not likely to have any consequences for the cell unless it ever needs to divide - which would be unusual for a terminally differentiated cell $(15,30,58)$. Recently, it has been reported that some cells potentially capable of proliferation such as circulating quiescent human B-lymphocytes also maintain high efficiency of their transcription-dependent repair at the expense of suppression of global repair, thus becoming prone to accumulation of DNA damage in the case when DNA damage and call for proliferation coincide (38). Obviously, very different mechanisms for making the decision when to repair and what to repair operate in undifferentiated and differentiated cells.

Not all individuals are equal in their ability to recognize and repair damage to their DNA in a timely fashion so as not to allow accumulation of unrepaired damage. The finding of the inter-individual variation in the capacity for DNA repair is 
actually one of the ideas that assisted in the emergence of the concept of personalized healthcare in the last decades of the $\mathrm{XX}$ century as it effectively led to abandoning of the notion that a 'clinically healthy' individual is healthy indeed. It was much later, however, that it was discovered that temporal distribution of the manifestations of the same traits may determine whether they are good or bad for the individual who carries them at a discrete time point. In the aspect of DNA repair, this was verified only in the last 10 years, as it was originally believed that any variations in the genes coding for proteins participating in DNA repair would present as severe inborn disease. Such diseases are considered rare (the most common, xeroderma pigmentosum, has incidence of about 1:250 $000-1: 500000$ live births) which is most probably related to the fact that many foetuses affected with inherited disease do not survive to term at all so they are not included in the statistics as genuine cases. It was only recently discovered that subtle polymorphic variants in some genes coding DNA repair proteins or chromatin-modifying molecules such as HMGA1 are quite common and fully compatible with life within and outside the womb, but may prove troublesome in later life. Such are, for example, the substitutions C8092A in ERCC1, Arg194Trp and Arg399Gln in XRCC1 and Lys751Gln in XPD. These polymorphisms seemingly do not have other significant effect on the health of the carrier apart from increasing the risk for development of cancer in middle and advanced age $(40,92)$. Some polymorphisms in the XPD gene (312Asn and, again, Lys751Gln) may bring about an increase in the risk for senile cataract in carrier individuals, probably because of accelerated aging of the crystallins in the lens of the eye (81). Since risk of cancer generally increases with age, it is quite obvious that such polymorphic variants would fully exert their adverse effect late in life. Their genetic carriership was probably not selected against in the process of human evolution (as we said before, the average lifespan of humans increased beyond late adulthood only in the last century or so), which makes these polymorphisms likely to be common in all populations. It is still unclear whether they convey any selective advantage in early life, but it seems that at least some DNA repair genes do play a role in individual development. Recently, P53, the ultimate tumour-suppressor gene, has also been reviewed in the light of the antagonistic pleiotropy theory, as it has been found that a combination of polymorphic variants of $P 53$ and $X R C C 1$ genotypes is associated with increased lung cancer risk in younger smokers but not in older smokers, while the wildtype allele combination increased lung cancer risk for individuals over the age of 60 (17). Similar studies have been conducted for association with certain P53 genotypes and fertility in humans (41). Thus, wildtype p53 increases the opportunity to pass one's genetic background to the progeny by increasing the odds of successful reproduction at young age as well as by protecting the organism against cancer, but exert their deleterious effects later in life by promoting aging, which includes increased occurrence of cancer in the elderly (17, 41, 82). Methods for assessment of individual repair capacity are developing steadily $(4,12,16,22)$, therefore we could expect that opportunities for early detection of deficiencies in the capacity for DNA repair and intervention so as to prevent cancer and other adverse sequelae of accumulation of unrepaired DNA damage will become more efficient and more accessible in the near future.

It has been known for some years that the expression of proteins participating in the maintenance of the chromatin structure such as the transcription regulator HMGA1 may be deregulated in cancer $(13,28,74,77)$. Later, an unexpected relationship has been found between the levels of HMGA1 and a condition typical of middle age such as insulin resistance. Namely, a number of polymorphisms in the hmgal gene resulting in severe insulin resistance and pronounced hyperglycemia have been identified in animal models as well as in humans $(18,31)$. Hyperglycemia usually produces an increased level of oxidative stress and associated DNA damage in mitochondria (5), and, since the accumulation of unrepaired damage in DNA is considered a basic carcinogenic mechanism, it has been proposed that inherently low levels of HMGA1 expression (e.g. resulting from carriership of gene polymorphisms) may actually lead to decreased efficiency of protection of the DNA of the cell against oxidative damage. As a result, potentially carcinogenic oxidative lesions gradually accumulate, setting the basis for subsequent malignant transformation (62). This is, however, once again, an event that may occur only after sufficient time has passed, allowing the damaging agents to hit their target repeatedly and the level of unrepaired damage to accumulate sufficiently as to trigger tumorigenesis - that is, when the individual is old enough. It could be hypothesized, however, that the insulin-resistant phenotype and some associated metabolic features (capacity for accumulating fat depots, ketogenic metabolism) might have actually presented a selective advantage to young carrier individuals in the historical times when food was often sparse and life expectancy was low, resulting in some degree of positive selection or at least in very low negative selection for this trait - at least, until relatively recent times (see below).

\section{Back in my day we didn't have this: the emergence of aging-related diseases}

Middle age is when your age starts to show around your middle.

Bob Hope (1903-2003)

The scale of impact of age-related disease for the individuals affected by it as well as for the healthcare system has only begun to show. It could be expected that this is actually just 'the tip of the iceberg' and that the impact would continually increase in the next decades. As humans live longer, and their living conditions continue to improve, diseases and conditions related to aging that were seldom observed until not that long ago will readily emerge and develop on a global scale. It could be easily (and wrongly) assumed that all these 'new' diseases are a product of lifestyle and/or environmental factors and some of them indeed are (e.g. obesity). The grounds for these 
erroneous assumptions could be best described as a post hoc fallacy. As age-related diseases, as their name shows, manifest relatively late in life, the short life expectancy of pre-modern people practically eliminated the affected individuals before their conditions could become apparent but oftentimes after they have passed their genes to the offspring. Also, many agerelated diseases and diseases that develop only a sufficient period of time after the initial encounter with the putative causative or triggering agent has passed are often preceded by other conditions which are now treatable or at least manageable. This means that while once the affected individuals often died because of the condition, nowadays, provided that the affected individual survives the initial attack, it is likely that the risk for the respective disease of aging to develop with time increases. Examples are numerous. It is well known from clinical practice that myelodysplastic syndromes (MDS) often precede (sometimes by decades) the development of overt leukemia $(59,78)$. Myelodysplasias may produce potentially life-threatening incidents on their own (e.g. bleeding diathesis, reduced resistance to infectious disease) which before the advent of chemotherapy and the use of growth factors, such as erythropoietin and G-CSF, could be fatal, resulting in genuine reduction of the cases that would have potentially progressed to post-MDS leukemia. Post-streptococcal glomerulonephritis with subsequent renal failure and post-streptococcal rheumatic endocarditis are common late complications of infections with beta-hemolytic streptococci even today, but as recently as a century ago it was much more likely for the patient to die from the infection itself than from its late sequelae. Finally, diabetic ketoacidosis may be life-threatening even in modern settings; therefore, back in the times when etiological treatment was not available this condition was likely to kill the affected person before the late complications associated with prolonged hyperglycemia (e.g. metabolic syndrome) could develop.

As of now, the role of antagonistic pleiotropy in human disease is studied intensively, as, apart from the obvious reason related to the differential patterns of aging of the global population; there are a number of human diseases and conditions which seem to be associated with carriership of certain alleles in different genes but have a significant, albeit difficult to evaluate association with environmental or chance factors as well. In other words, they are clearly heritable, according to data gathered by familial studies, but also seem to be dependent on other factors, therefore they have significant prevalence in all populations, and yet it is very hard to assess the risk for the disorder for the particular individual. Such are, for example, schizophrenia (about $1 \%$ in all populations), affective disorders (between 10 and $20 \%$ in all populations) and some autistic spectrum disorders $(0.1 \%-0.5 \%$ in populations where DSM-IV criteria are promptly followed, excluding Rett's disorder as a proportion of the cases have been traced to be associated with a defect in a single gene) $(1,44)$. Recently it has been proposed that these and other conditions are related to receiving an inappropriately high dosage of alleles which, in lesser doses, confer some positive advantage (43). Too high a gene dosage may be taxing and indeed, patients with schizophrenia or severe autism do have significant reduction in physical fitness coupled with reproductive disadvantage - for a variety of reasons. It is known that the lifespan in schizophrenia and bipolar disorder is often shorter than in the general population and that this is usually related to physical disease (metabolic syndrome, hyperlipidemia, cardiovascular disease, etc.) $(24,57)$. So far, however, the parameters of the proposed dosage effect and the elusive selective advantage of a smaller gene dosage have not been identified yet.

Obesity is a major health problem on a global scale today and much research effort has been invested in unraveling the mechanisms that resulted in the impressive prevalence of obesity we see in modern societies. The 'thrifty gene' hypothesis proposes that allelic forms of certain genes have been selected for during evolution because of the singular advantage they confer to the carrier, namely, the capacity for fat storage $(75,87,88)$. Apparently, lean metabolism has always been a luxury during human existence, as only individuals who had enough depots of fat stored when food was plentiful could survive periods of famine. Mild to moderate insulin resistance produces this 'thrifty' phenotype, as hyperglycemic states are associated with inhibition of lipolysis, causing accumulation of fat into lipid storage depots. When food is sparse, adipocytes of insulin resistant individuals hydrolyze readily the stored triglycerides, releasing fatty acids in the plasma to be used as fuel by the glucose-starved cells, allowing the individual to survive and pass their 'thrifty' genes on during famine while other, less 'thrifty' metabolizers, may die or at least their reproductive fitness would decline. Therefore, ability to use energy sparingly must have been an asset back in the times when reaching old age was a rare event, as insulin resistance usually develops insidiously and may precede overt diabetes type II with years or even decades. Nowadays, however, people have a very good chance of living beyond the age when prolonged hyperglycemia ultimately takes its toll, therefore the associated evolutionary advantage which has been selected for many centuries may eventually turn to a disadvantage in the modern man.

\section{Eat right, exercise regularly, die anyway - do popular health fads and misconceptions have any scientific basis at all?}

Let Time that makes you homely, make you sage, The sphere of wisdom is the sphere of age.

Thomas Parnell, An Elegy to an Old Beauty (circa 1710), 1.

There are numerous popular concepts related to behaviours or goals that are believed to be 'healthy' or to promote longevity. Here we would only deal with those which have a scientific basis, as all the others are a legion and some of them hardly deserve attention.

The most commonly exploited 'living healthy' notions supported by research data are: maintaining low total cholesterol levels; prevention of hypercoagulable states (i.e. 
the 'an aspirin a day' notion); abstaining from drinking alcohol; physical exercise, etc. Extensive surveys among people who qualify for the 'extreme longevity' category ( $\geq 85$ at the time of the interview), show, however, that the distribution of behaviour patterns (including habits related to personal health) among these oldest old does not differ significantly from that seen in the general population $(68,91)$. Moreover, it has been recently shown that hypercoagulability is actually compatible with successful aging and longevity $(54,83)$ and - surprisingly - that total cholesterol levels over $5 \mathrm{mmol} / \mathrm{l}$ in the age group over 70 years are positively associated with longevity owing to lower mortality from cancer and infection in the $>5 \mathrm{mmol} / \mathrm{l}$ experimental subgroup $(79,89)$. This phenomenon could find its explanation in reverse antagonistic pleiotropy, that is, elevated cholesterol levels may contribute to morbidity and mortality in young age and adulthood via increasing the risk for development of vascular disease but, with age, via mechanism/s as of now unknown, this begins to be more of a selective advantage than a disadvantage.

Somewhat similar is the situation with the control over body weight. It has been known for quite a long time that calorie deprivation of laboratory animals (about $60-70 \%$ of the amount of kilocalories the animal would have if fed ad libitum) extends their life and lowers the incidence of cancer and other age-related disease, possibly because of the decreased levels of oxidative stress $(27,49)$. It is, however, also known from clinical practice that people who are mildly overweight are more likely to survive and develop complications more rarely after acute events (e.g . incidences of atrial fibrillation) as well as in the course of a chronic disease (e.g. non-diabetic kidney failure) compared to their underweight and even normal weight counterparts $(2,48)$. It is only fair to note that in serious chronic disease it is more likely that patients in more advanced stage of the disease (and, therefore, more likely to develop complications) would be underweight, and that new-onset atrial fibrillation is more likely to develop in obese people (86). Still, such research results do raise interesting questions as to whether it is really good for anyone to try to conform to the Western ideal body image.

Many studies have elicited an inverse relationship between regular exercise and the risk of certain cancers (37). However, a differentiation ought to be made between physical activity that is physiologically compatible (with regards to gender, age, physical fitness, etc. of the individual) and inappropriate, often strenuous physical exercise. It has been repeatedly shown in animal models and in humans as well that intense physical exercise is accompanied by elevation of oxidative stress not only in the working muscles but in other tissues and organs as well $(3,55)$. Oxidative stress is recognized as a major factor in carcinogenesis, therefore, it is possible that too much exercise may produce the exact opposite of the health advantages claimed to be associated with moderate exercise.

Finally, it has been demonstrated that relative risks for coronary heart disease and stroke (conditions typically associated with aging) are actually reduced by moderate consumption of alcoholic beverages. In other words, the prevalence of cardiovascular disease and stroke has been found to be actually higher in non-drinkers than in moderate drinkers $(51,63)$. Lately, it has been demonstrated that nonbinge drinking actually reduces the risk of cognitive decline and dementia in adult and old age $(19,56)$. While the line between alcohol use and alcohol abuse is very thin and it is therefore advisable not to drink at all, once again, this is a 'healthy living' concept that requires careful evaluation.

\section{Could we really do anything in order to age successfully?}

Age is strictly a mind over matter. If you don't mind, then it doesn't matter.

Mark Twain (1835-1910)

Several properties associated with successful aging have been defined, among which two basic categories could be defined, namely, traits that are associated with actual physical health status and qualities related to personality and general attitude to life. Of the first category, the general characteristics considered to be related to increased chances for successful aging are less-than-usual for the age group health trouble (no diabetes, no cancer, no serious mental disease) and preserved cognitive and physical capacity (to an extent, depending on the actual age (e.g. 'walks for exercise' vs. 'capable and/or willing to walk should the need arise'). The second type of properties is considered no less important than the first and comprises active engagement/satisfaction with life, general optimistic mindset towards life; and one's spouse alive and (relatively) healthy $(46,70,76)$.

Another trait associated with longevity and successful aging seems to be appropriate physical activity, both leisure and non-leisure (possibly related to the fact that having a physically active job would compel the person to be more active than having a sedentary job). This seems to exert its beneficial effects on both components found to be associated with successful aging so far, i.e. the physical as well as the psychological status $(23,50,52)$.

All these traits positively associated with successful aging do have one common unifying feature - independence, both physical and psychological. It seems that the major prognostic factor for aging gracefully is sustained independence, which is only natural even in a purely physical aspect as people who suffer from serious diseases are much less likely to be independent. Both groups of traits characteristic of successful aging seem to be important and while neither could actually exist without the other; both could exert a synergistic effect towards living a long and full life. Modern medicine offers many opportunities to prevent or delay adverse health events (e.g. cancer screening, antidiabetic therapy, antihypertensive medication) and, with the advent of methodology for assessment of individual repair capacity, it could be expected that the process of making informed decisions so as to decrease the risk of late-age disease would be greatly facilitated in the near future. Moreover, several strategies 
designed to ensure protection against one of the major proaging and carcinogenic factors - the UV radiation - even after prolonged or repeated encounter with it, have been developed $(7,14,21,80)$. Also, the anticancer and anti-inflammatory properties of some substances commonly found in human food and beverages such as resveratrol and antocyanes in fresh fruit and vegetables, polyphenols in tea and coffee, compounds in herbs and spices such as curcumin, etc. have been thoroughly studied and confirmed $(39,42,47,61)$. The other major factor, however, the positive attitude and genuine interest in life are often solely dependent on the attitude of the person. Therefore, living healthy is only one component of being healthy; living well is the other, without the latter the former does not seem to work as expected.

\section{Conclusions}

To die healthy means to live well. Robert Green Ingersoll (1833 - 1899)

It has been proposed that centuries of human evolution have created a selection trend for traits that confer a selective advantage in the young while being disadvantageous in the elderly, termed antagonistic pleiotropy. The exploration of this area has just begun, as it was only in the last 100-150 years that the lifespan of the average human began to extend beyond several years after reproductive age and 'successful aging' became more than a phenomenon. Consequently, the scale and scope of the impact of age-related disease began to show and called for a new concept of the focus and the quality of the medical care in the modern society. As could be expected, in an effort to sustain active life in old age, along with the concepts supported with extensive research data, numerous health and longevity misconceptions also emerged. It could be only through careful research and assessment that the factors playing a role in the constitution of the phenotype of successful aging could be identified and only after that a strategy for increasing the chances for a long life including graceful aging could be devised.

\section{Acknowledgements}

This research was partially supported by grants No. DO0269 and DMU 03/112 of the Ministry of Education, Youth and Science of the Republic of Bulgaria.

\section{REFERENCES}

1. Amir R.E., Van den Veyver I.B., Wan M., Tran C.Q., Francke U., Zoghbi H.Y. (1999) Nature Genet., 23, 185188.

2. Badheka A.O., Rathod A., Kizilbash M.A., Garg N., Mohamad T., Afonso L., Jacob S. (2010) Am. J. Med., 123(7), 646-651.

3. Bar-Shai M., Carmeli E., Ljubuncic P., Reznick A.Z. (2008) Free Radic. Biol. Med., 44(2), 202-214.
4. Bartsch H., Dally H., Popanda O., Risch A., Schmezer P. (2007) Recent Results Cancer Res., 174, 19-36.

5. Baynes J.W. (1991) Diabetes, 40, 405-412.

6. Bohr V.A. (1987) Dan. Med. Bull., 34(6), 309-320.

7. Cafardi J.A., Elmets C.A. (2008) Expert Opin. Biol. Ther., 8(6), 829-838.

8. Candore G., Lio D., Colonna Romano G., Caruso C. (2002) Autoimmun Rev., 1(1-2), 29-35.

9. Candore G., Balistreri C.R., Campagna A.M., Colombo A., Cuppari I., Di-Carlo D., Grimaldi M.P., Orlando V., Piazza G., Vasto S., Lio D., Caruso C. (2006) Ann. N.Y. Acad. Sci., 1089, 509-515.

10. Caruso C., Candore G., Colonna Romano G., Lio D., Bonafè M., Valensin S., Franceschi C. (2000) Hum. Immunol., 61(9), 942-949.

11. Caruso C., Candore G., Romano G.C., Lio D., Bonafè M., Valensin S., Franceschi C. (2001) Mech. Ageing. Dev., 122(5), 445-462.

12. Chakarov S., Stoilov P., Alexandrov A., Russev G. (1997) Eur. J. Biochem. 248, 669-675.

13. Chakarov S., Chakalova L., Tencheva Z., Ganev V., Angelova A. (2000) Life Sci., 66(18), 1725-1731.

14. Chakarov S.A., Petkova R.D., Russev G.Ch. (2008) Biotechnol. Biotech. Eq., 22(4), 1011-1012.

15. Chakarov S., Russev G. (2010) Biotechnol. Biotech. Eq., 24(2), 1804-1806.

16. Chakarov S., Roeva I., Russev G. (2011) Biotechnol. Biotech. Eq., 25(3), 2505-2507.

17. Cherdyntseva N.V., Gervas P.A., Litvyakov N.V., Stakcheeva M.N., Ponomaryeva A.A., Dobrodeev A.Y., Denisov E.V., Belyavskaya V.A., Choinzonov E.L. (2010) Exp. Oncol., 32(3), 205-208.

18. Chiefari E., Tanyolaç S., Paonessa F., Pullinger C.R., Capula C., Iiritano S., Mazza T., Forlin M., Fusco A., Durlach V., Durlach A., Malloy M.J., Kane J.P., Heiner S.W., Filocamo M., Foti D.P., Goldfine I.D., Brunetti A. (2011) JAMA, 305, 903-912.

19. Collins M.A., Neafsey E.J., Mukamal K.J., Gray M.O., Parks D.A., Das D.K., Korthuis R.J. (2009) Alcohol Clin. Exp. Res., 33(2), 206-219.

20. Curtin L.R., Klein R.J. (1995) Direct Standardization (Age-Adjusted Death Rates), Statistical Notes, No. 6., National Center for Health Statistics, Hyattsville, Maryland..

21. DeBoyes T., Kouba D., Ozog D., Fincher E., Moy L., Iwata K., Moy R. (2010) J. Drugs Dermatol., 9(12), 15191521.

22. Decordier I., Loock K.V., Kirsch-Volders M. (2010) Mutat. Res., 705(2), 107-129.

23. Di Francesco V., Zamboni M., Zoico E., Bortolani A., Maggi S., Bissoli L., Zivelonghi A., Guariento S., Bosello O. (2005) Aging Clin. Exp. Res., 17(3), 201-206. 
24. DE Hert M., Correll C.U., Bobes J., Cetkovich-Bakmas M., Cohen D., Asai I., Detraux J., Gautam S., Möller H.J., Ndetei D.M., Newcomer J.W., Uwakwe R., Leucht S. (2011)World Psychiatry, 10(1), 52-77.

25. Drake J.W., Charlesworth B., Charlesworth D., Crow J.F. (1998) Genetics, 148(4), 1667-1686.

26. Erickson E. (1959) Psychol. Issues, 1(1), 171.

27. Fair A.M., Montgomery K. (2009) Methods Mol. Biol., 472, 57-88.

28. Fedele M., Fusco A. (2010) Biochim. Biophys. Acta, 1799, 48-54.

29. Fensterle J., Trefzer U., Berger T., Andersen M.H., Ugurel S., Becker J.C. (2006) BMC Med., 4, 5.

30. Fortini P., Dogliotti E. (2010) Mutat. Res., 685(1-2), 3844.

31. Foti D., Chiefari E. Fedele M., Iuliano R., Brunetti L., Paonessa F., Manfioletti G., Barbetti F., Brunetti A., Croce C.M., Fusco A., Brunetti A. (2005) Nat. Med., 11, 765-773.

32. Gosden R.G. (1987) Hum Reprod., 2(7), 617-621.

33. Grabowski D.C., Campbell C.M., Morrisey M.A. (2004) JAMA, 291(23), 2840-2846.

34. Hanawalt P.C. (1989) Genome, 31, 605-611.

35. Hanawalt P.C. (2001) Environ. Mol. Mutagen., 38, 89-96.

36. Hodges S. (2002) Lorenzo Da Ponte: The Life and Times of Mozart's Librettist, Univ. of Wisconsin Press.

37. Hursting S.D., Lashinger L.M., Colbert L.H., Rogers C.J., Wheatley K.W., Nunez N.P., Mahabir S., Barrett J.C., Forman M.R., Perkins S.N. (2007) Curr. Cancer Drug Targets, 7(5), 484-491.

38. Hyka-Nouspikel N., Lemonidis K., Lu W.T., Nouspikel T. (2011) Blood, 117(23), 6277-6286.

39. Jagdeo J., Brody N. (2011) J. Drugs Dermatol., 10(7), 753-761.

40. Jiang J., Zhang X., Yang H., Wang W. (2009) Methods Mol. Biol., 47, 305-333.

41. Kang H.J., Feng Z., Sun Y., Atwal G., Murphy M.E., Rebbeck T.R., Rosenwaks Z., Levine A.J., Hu W. (2009) Proc. Natl. Acad. Sci .U.S.A., 106(24), 9761-9766.

42. Kris-Etherton P.M., Hecker K.D., Bonanome A., Coval S.M., Binkoski A.E., Hilpert K.F., Griel A.E., Etherton T.D. (2002) Am. J. Med., 113, Suppl 9B, 71S-88S.

43. Keller M.C., Miller G. (2006) Behav. Brain Sci., 29(4), 385-404.

44. Kessler R.C., McGonagle K.A., Zhao S., Nelson C. B., Hughes M., Eshleman S., Wittchen H.-U., Kendler K.S. (1994) Arch. Gen. Psych., 51(1), 8-19.

45. Klein R.J., Schoenborn C.A. (2001) Age-Adjustment Using the 2000 Projected U.S. Population, Statistical Notes, No. 20, National Center for Health Statistics, Hyattsville, Maryland.
46. Lacruz M.E., Emeny R.T., Bickel H., Cramer B., Kurz A., Bidlingmaier M., Huber D., Klug G., Peters A., Ladwig K.H. (2010) BMC Med. Res. Methodol., 10, 36.

47. de la Lastra C.A., Villegas I. (2007) Biochem. Soc. Trans., 35(Pt 5), 1156-1160.

48. Lea J.P., Crenshaw D.O., Onufrak S.J., Newsome B.B., McClellan W.M. (2009) Obesity (Silver Spring), 17(12), 2216-2222.

49. Lee G.D., Wilson M.A., Zhu M., Wolkow C.A., de Cabo R., Ingram D.K., Zou S. (2006) Aging Cell, 5(6), 515524.

50. Leino-Arjas P., Solovieva S., Riihimäki H., Kirjonen J., Telama R. (2004) Occup. Environ. Med., 61(12), 10321038.

51. Letenneur L. (2004) Biol Res., 37(2), 189-193.

52. Lin Y.P., Huang Y.H., Lu F.H., Wu J.S., Chang C.J., Yang Y.C. (2011) BMC Public Health, 11, 428.

53. Lindahl T. (1993) Nature, 362(6422), 709-715.

54. Mari D., Coppola R., Provenzano R. (2008) Exp. Gerontol., 43(2), 66-73.

55. Na H.K., Oliynyk S. (2011) Ann. N.Y. Acad. Sci., 1229(1), 176-183.

56. Neafsey E.J., Collins M.A. (2011) Neuropsychiatr. Dis. Treat., 7, 465-484.

57. Newcomer J.W. (2007) Am. J. Manag. Care, 13(7 Suppl.), S170-177.

58. Nouspikel T., Hanawalt P.C. (2002) DNA Repair (Amst), 1(1), 59-75.

59. Orlandi E., Alessandrino E.P., Caldera D. Bernasconi C. (1988) Acta Haematol., 79(3), 174-177.

60. Papasteriades C., Boki K., Pappa H., Aedonopoulos S., Papasteriadis E., Economidou J. (1997) Gerontology, 43(3), 176-181.

61. Patel V.B., Misra S., Patel B.B., Majumdar A.P. (2010) Nutr. Cancer, 62(7), 958-967.

62. Petkova R., Tummala H., Zhelev N. (2011) Biotechnol. Biotech. Eq., 25(4), 2572-2575.

63. Pinder R.M, Sandler M. (2004) J. Psychopharmacol., 18(4), 449-456.

64. Pöpper T., Thoenes C., Zöllner F. (2010) Michelangelo, Complete Work, Taschen GmbH, Köln, Germany.

65. Pruchno R.A., Wilson-Genderson M., Rose M., Cartwright F. (2010) Gerontologist, 50(6), 821-833.

66. Price P., Witt C., Allcock R., Sayer D., Garlepp M., Kok C.C., French M., Mallal S., Christiansen F. (1999) Immunol. Rev., 167, 257-274.

67. Quinney B., McGwin G. Jr., Cross J.M., Valent F., Taylor A.J., Rue L.W. 3rd. (2002) J. Burn Care Rehabil., 23(5), 305-310. 
68. Rajpathak S.N., Liu Y., Ben-David O., Reddy S., Atzmon G., Crandall J., Barzilai N. (2011) J. Am. Geriatr. Soc., 59(8), 1509-1512.

69. Rogers R.G., Everett B.G., Onge J.M., Krueger P.M. (2010) Demography, 47(3), 555-578.

70. Roos N.P., Havens B. (1991) Am. J. Pub. Health, 81(1), 63-68.

71. Rowe J.W. (1987) Geriatrics, 42, 99-100.

72. Rowe J.W., Kahn R.L. (1987) Science, 237(4811), 143149.

73. Rowe J.W., Kahn R.L. (1997) Gerontologist, 37(4), 433440.

74. Sgarra R., Rustighi A., Tessari M.A., Di Bernardo J., Altamura S., Fusco A., Manfioletti G., Giancotti V. (2004) FEBS Lett., 574, 1-8.

75. Stipp D. (2011) Aging (Albany NY), 3(2), 85-93.

76. Strawbridge W.J., Cohen R.D., Shema S.J., Kaplan G.A. (1996) Am. J. Epidemiol., 144(2), 135-141.

77. Tencheva Z., Velichkova A., Chakarov St. (1995) Compt. Rend. Acad. Bulg. Sci., 48(6), 101-104.

78. Tichelli A., Gratwohl A., Würsch A., Nissen C., Speck B. (1988) Ann. Hematol., 56(2), 79-81.

79. Tuikkala P., Hartikainen S., Korhonen M.J., Lavikainen P., Kettunen R., Sulkava R., Enlund H. (2010) Scand. J. Prim. Health Care, 28(2), 121-127.

80. Tummala H., Khalil H., Zhelev N. (2011) Biotechnol. Biotech. Eq., 25(3), 2443-2446.
81. Unal M., Güven M., Batar B., Ozaydin A., Sarici A., Devranoğlu K. (2007) Exp. Eye Res., 85(3), 328-334.

82. Ungewitter E., Scrable H. (2009) Mech. Ageing Dev., 130(1-2), 10-17.

83. Vaccarino L., Forte G.I., Palmeri M., Misiano G., Porcellini E., Chiappelli M., Scola L., Caruso C., Licastro F., Lio D. (2011) Biogerontology, 12(5), 445-450.

84. Vaillant G.E., Mukamal K. (2001) Am. J. Psychiatry, 158(6), 839-847.

85. Wallace W.H.B., Kelsey T.W. (2010) PLoS One, 5(1), e8772.

86. Wang T.J., Parise H., Levy D., D'Agostino R.B. Sr., Wolf P.A., Vasan R.S., Benjamin E.J. (2004) JAMA, 292(20), 2471-2477.

87. Wells J.C. (2006) Biol. Rev. Camb. Philos Soc., 81(2), 183-205.

88. Wells J.C. (2011) Am. J. Hum. Biol., 23(1), 65-75.

89. Weverling-Rijnsburger A.W., Blauw G.J., Lagaay A.M., Knook D.L., Meinders A.E., Westendorp R.G. (1997) Lancet, 350(9085), 1119-1123.

90. Williams G.C. (1957) Evolution, 11, 398-411.

91. Yates L.B., Djoussé L., Kurth T., Buring J.E., Gaziano J.M. (2008) Arch. Intern. Med., 168(3), 284-290.

92. Yin Z., Su M., Li X., Li M., Ma R., He Q., Zhou B. (2009) J. Exp. Clin. Cancer Res., 14(28), 53. 